\title{
New Nafion/Conducting Polymer Composite for Membrane Application
}

\author{
So-Jeong Lee ${ }^{1}$, Nallal Muthuchamy ${ }^{1}$, Anantha-Iyengar Gopalan ${ }^{2,3}$ and Kwang-Pill Lee ${ }^{1,2,3, *}$ \\ ${ }^{1}$ Department of Chemistry Education, Kyungpook National University, Daegu 41566, Republic of Korea \\ ${ }^{2}$ Research Energy Institute of Advanced Technology, Kyungpook National University, Daegu 41566, Republic of Korea \\ ${ }^{3}$ Department of Nanoscience and Nanotechnology, Kyungpook National University, Daegu 41566, Republic of Korea \\ ${ }^{*}$ Corresponding author
}

\begin{abstract}
Membrane separation technology is one of the most innovative and steadily growing fields across science and engineering. The performance of a membrane is determined by several key properties: high selectivity and permeability; excellent chemical, thermal, and mechanical stability under the process operating conditions; low maintenance; good space efficiency; and defect free conditions. The most commonly used membrane in fuel cell technology is Nafion, which relies on liquid water humidification of the membrane to transport protons. This implies that it is not feasible to use temperatures above $80-90^{\circ} \mathrm{C}$, since the membrane would dry. Recent studies on the surface modification of Nafion membranes involved doping with other polymers, plasma treatment, and electron beam treatment. In this study, modification of Nafion was done using conducting polymer such as poly(dipheylamine) (PDPA) to reduce the methanol crossover in direct methanol fuel cell applications.
\end{abstract}

Keywords-nafion; conducting polymer; polydiphenylamine; PANI; fuel cell

\section{INTRODUCTION}

Nafion was initially developed by DuPont in the late 1960s to meet the demands of the chloro-alkali industry. Later on, Nafion has found usage in a broad range of applications such as dialysis and water purification and has during the last 30 years [1-2], without doubt, become one of the major reasons for the intensive research on proton exchange fuel cell. The perfluorinated backbone structure of Nafion is similar to that of teflon and is strongly hydrophobic. As opposed to the polymer backbone, the short spacer including the proton conducting sulfonic acid group is very hydrophilic and a micro phase separation is obtained in the membrane. A number of studies have been performed with the goal of developing alternative membranes, focusing on the reduction of the methanol permeability. These studies were generally divided into two categories. The first was to develop new synthetic polymeric membranes that have ionic clusters with a small percolation size. These include sulfonated poly(ether ether ketone) (PEEK) [3], poly(arylene ether sulfone) [4], poly(vinylidene fluoride) (PVdF)/polytetrafluoroethylene (PTFE)-graft-polystyrene sulfonic acid (PSSA) and their blends or copolymerizations with other polymeric materials [5]. The second was to modify the Nafion membranes by surface treatment or by blending them with other polymer/inorganic materials. Nafion/silicon oxide composite [6], and Nafion/poly(vinylidene fluoridehexafluoropropylene) blended membranes [7] are good examples of this category. Studies on the surface modification of Nafion membranes have been directed on doping with other polymers [8], plasma treatment, and electron beam treatment [9]. Won et al. [10] reported interesting results concerning the effect of polymer crosslinking on the proton and methanol transport properties. The crosslinking of sulfonated poly(styrene- b-butadieneb- styrene) (SBS) reduced the water swelling ratio, and consequently, the methanol transport rate. Buchi et al. [11] prepared poly(tetrafluoroethylene - co hexafluoropropylene) (FEP)-g-crosslinked PSSA membranes by the radiation grafting method. The introduction of the crosslinking agent during grafting polymerization improved the fuel cell performance by reducing the gas permeability.

To date, Nafion is still the most performing cationexchange membrane due to its high chemical and mechanical stability as well as its good proton conductivity. The modification of Nafion membranes using inorganic fillers such as $\mathrm{SiO}_{2}$, mordenite, inorganic acids, a polymer coating and/or filler such as poly(vinyl alcohol), poly(1-vinylimidazole), and poly(vinylidene fluoride) have been studied earlier. It is thought that the modification of an ion selective polymer with a second polymer characterized by a rigid structure may help to increase the selectivity of the membrane to the required ions, while at the same time maintaining REASONABLY HIGH PERMEABILITY. A small group of studies has declared its interest in the production of a new type of separation membrane [12].

Modification of Nafion was done using conducting polymers such as poly(pyrrole) and poly(aniline) (PANI) to reduce the methanol crossover in direct methanol fuel cell applications. However, some progress is still needed in order to enhance the membrane performance in terms of permselectivity, water management, and stability at high temperatures. Polydiphenylamine (PDPA), N-substituted PANI derivative was known to possess electrochemical and optical characteristics different from the other N-substituted PANI derivatives. Hence, a modification of Nafion with PDPA is expected to improve the existing limitations of Nafion. In the present investigation, composite membranes of Nafion with PDPA were prepared and their structure, morphology, thermal properties were studied. The ionexchange capacity of Nafion/PDPA membranes was determined by atomic adsorption spectrophotometry. 


\section{EXPERIMENTAL}

\section{A. Chemicals}

Sulfuric acid (98.0\%), ammonium persulfate (APS) $(99.99 \%)$, sodium chloride $(98.0 \%)$, potassium chloride $(99.5 \%)$ were received from Aldrich (USA) of reagent grade and used as received. Diphenylamine (DPA) (99\%) from Aldrich (USA) was distilled prior to use. Distilled water was used for the preparation of all solutions.

\section{B. Instruments}

The morphology of the membranes were examined by field emission scanning electron microscope (FESEM) (Hitachi, S4200, New York, USA) with a field emission gun operated at $200 \mathrm{kV}$.Atomic force microscope (AFM) image of the composite membranes were recorded in the tapping mode using a SPM (Digital Instruments; Nanoscope Multimode) (JEOL Tokyo, Japan) with an etched silicon aluminum coated tip for examining the roughness of the surface of composite membrane. Ion-exchange capacity measurements were performed by atomic absorption spectrophotometer (Varian, SpectraAA 220FS, USA).

\section{Preparation of Composite Membranes}

$\mathrm{H}_{2} \mathrm{O}_{2}(3 \% \mathrm{v} / \mathrm{v}), \mathrm{H}_{2} \mathrm{O}, \mathrm{H}_{2} \mathrm{SO}_{4}(0.50 \mathrm{M})$, and $\mathrm{H}_{2} \mathrm{O}$ were used in pretreatment process of membrane. All concentrations of solutions used in this study were prepared on the basis of the prior study [13]. Membrane was conditioned in $3.00 \mathrm{M} \mathrm{HCl}$ for more than $24 \mathrm{~h}$ prior to modification. The modification was carried out by polymerizing DPA using APS as an oxidizing agent. The modified membranes were stored in $1.00 \mathrm{M} \mathrm{H}_{2} \mathrm{SO}_{4}$ solutions. Every composites membranes were prepared by varying the polymerization time from 1-4 hrs. A following scheme is presented to show the procedure for the preparation of the composite membrane.

\section{Membrane Characterization}

The morphology of the membranes was examined by field emission scanning electron microscope (FESEM) with a field emission gun operated at $200 \mathrm{kV}$. Atomic force microscope (AFM) image of the composite membrane was recorded in the tapping mode using a SPM with an etched silicon aluminum coated tip. Samples were only partially dried with a nitrogen flow to remove surface water. Ion-exchange capacity measurements were performed by atomic absorption spectrophotometer.

The procedure for ion-exchange capacity analysis is outlined. All membranes were washed and stabilized in 1.00 $\mathrm{M} \mathrm{HCl}, \mathrm{H}_{2} \mathrm{O}$, and $1.00 \mathrm{M} \mathrm{NaCl} / \mathrm{KCl}$ alternatively for $2 \mathrm{~h}$ in each solution. The membranes were then soaked for $2 \mathrm{~h}$ in a $1.00 \mathrm{M} \mathrm{NaCl} / 1.00 \mathrm{M} \mathrm{KCl}$ solution to ion-exchange $\mathrm{H}^{+}$with $\mathrm{Na}^{+}$or $\mathrm{K}^{+}$ions. After removing excess sodium chloride/potassium chloride (by immersion in water for $30 \mathrm{~min}$ and rinsing with water), the membranes were dried under vacuum at room temperature for at least $36 \mathrm{~h}$. The $\mathrm{Na}^{+} / \mathrm{K}^{+}$ ions were ion-exchanged with $\mathrm{H}^{+}$by immersion in a $1.00 \mathrm{M}$ $\mathrm{HCl}$ solution for $24 \mathrm{~h}$. The sodium/potassium concentration in the latter solution was determined by atomic absorption spectrophotometer. The procedure for the ion-exchange capacity analysis (FIGURE-I (A)).
A)

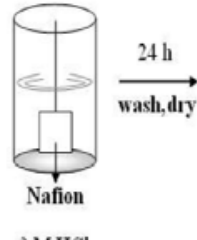

$3 \mathrm{MHCl}$

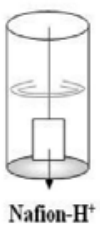

DPA in $3 \mathrm{MHCl}$

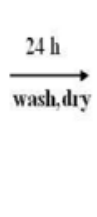

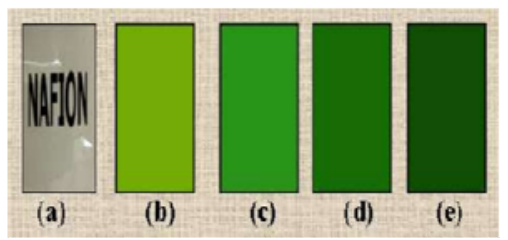

FIGURE I. (A) PREPARATION STEPS OF COMPOSITE MEMBRANES AND (B) VISUAL PHOTOGRAPH OF (A) NAFION (B-E) NAFION/PDPA-CM MEMBRANES PREPARED AT DIFFERENT POLYMERIZATION TIME; ( $\mathrm{B}=1 \mathrm{HRS}, \mathrm{C}=2 \mathrm{HRS}, \mathrm{D}=3 \mathrm{HRS}, \mathrm{E}=$ 4 HRS)

\section{RESUlts AND DisCUSSION}

\section{A. Preparation of Nafion/PDPA Composite Membrane}

Modification of Nafion membrane was done by polymerizing DPA on to Nafion membrane to result Nafion/PDPA composite. The modification was carried out in two steps at room temperature. The first step involved the exchanging of protons in the membrane with protonated DPA. At first instant, the Nafion membranes were placed in a beaker consisting of $40.0 \mathrm{~mL}$ of $0.100 \mathrm{M} \mathrm{DPA}$ solution in $3.00 \mathrm{M}$ $\mathrm{HCl}$. After a specified time $(24 \mathrm{hrs})$, the membranes were taken out and rinsed with water. After rinsing with water, the DPA solution was replaced by $40.0 \mathrm{~mL}$ of $1.00 \mathrm{M}\left(\mathrm{NH}_{4}\right)_{2} \mathrm{~S}_{2} \mathrm{O}_{8}$ solution. This step polymerizes the DPA species exchange within the membrane. The modified membranes were stored in $1.00 \mathrm{M} \mathrm{H}_{2} \mathrm{SO}_{4}$ solution. Different composite membranes were prepared by varying the polymerization time from $1-4 \mathrm{hrs}$ and designated as Nafion/PDPA-CMX where $\mathrm{X}$ stands for duration of polymerization ( $\mathrm{X}=1,2,3$ and 4 hours). The scheme in FIGURE-I (B) presents the color change of the composite membrane depending on polymerization time. The composite membranes were changed the color from green to dark green depending on polymerization time.

\section{B. Morphology of Nafion and Nafion/PDPA}

FESEM and AFM analysis was performed to identify morphological changes happening on the surface as well as inside the microstructure of Nafion. FESEM measurement of the membranes were performed under different magnifications $(1$ and $5 \mu \mathrm{m})$. FESEM images of Nafion, Nafion/PDPA-CM-1 and the cross section view of Nafion/PDPA-CM-1 membranes are shown in the FIGURE-II (a-c). No pores were detected in Nafion membrane. The presence of typical PDPA particles was clearly observed in the Nafion/PDPA-CM-1 membrane. A similar morphological change was notified in the modification of Nafion with polypyrrole [14]. Further, AFM was used to 
find the rough ness of the surface. The roughness was determined for a scan area of $100 \mu \mathrm{m}^{2}$. FIGURE-II (d) shows the AFM topographical image Nafion/PDPA-CM-1. The mean roughness was found to be $\sim 40 \mathrm{~nm}$. A roughness of greater than $50 \mathrm{~nm}$ was reported [13]. The presence of PDPA on the surface and inside the Nafion membrane is evident from FESEM and AFM studies.

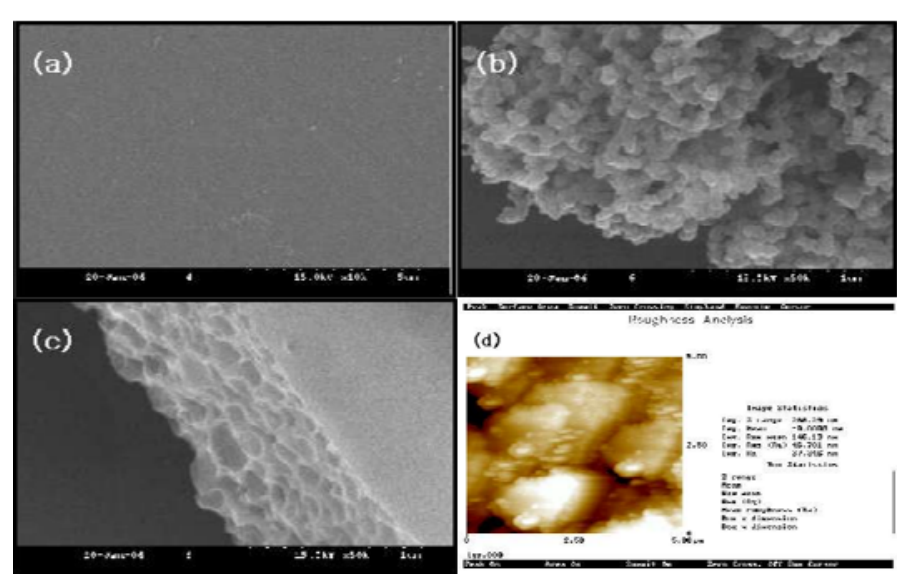

FIGURE II. FESEM IMAGE OF (A) NAFION (B) NAFION/PDPACOMPOSITE MEMBRANE (NAFION/PDPA-CM1), (C) CROSS SECTION VIEW OF NAFION/PDPA-CM1 AND (D) AFM IMAGE OF NAFION/PDPA-CM1

\section{Measurement of Ion Exchange Capacity}

TABLE I. ION EXCHANGE ABILITY OF NAFION/PDPA COMPOSITE MEMBRANE DETERMINED THROUGH AAS ANALYSIS

\begin{tabular}{|l|c|c|c|c|}
\hline Membrane & $\begin{array}{c}\text { *Concentration } \\
\text { of } \mathbf{K}^{+}\end{array}$ & ${ }^{*}$ IEC & $\begin{array}{c}\text { *Concentration }^{+} \\
\text {of Na }^{+}\end{array}$ & \#IEC \\
\hline Nafion [16] & 2.80 & 0.75 & 2.56 & 1.08 \\
\hline $\begin{array}{l}\text { Nafion/ } \\
\text { PDPA-CM1 }\end{array}$ & 0.95 & 0.24 & 0.97 & 0.39 \\
\hline $\begin{array}{l}\text { Nafion/ } \\
\text { PDPA-CM2 }\end{array}$ & 1.25 & 0.33 & 0.70 & 0.28 \\
\hline $\begin{array}{l}\text { Nafion/ } \\
\text { PDPA-CM3 }\end{array}$ & 0.56 & 0.16 & 2.19 & 0.89 \\
\hline $\begin{array}{l}\text { Nafion/ } \\
\text { PDPA-CM4 }\end{array}$ & & & & \\
\hline
\end{tabular}

* Concentration of $\mathrm{K}^{+}$and $\mathrm{Na}^{+}$were determined from AAS in ppm.

${ }^{\#}$ IEC in mequiv/g. All samples were measured after 10 1000 times dilution.

Ion-exchange capacity (IEC) measurements were performed to determine the variation in the amount of amine/imine groups compensated by sulfonate groups, in Nafion/PDPA composites membranes. The ion exchange capacity of the Nafion/PDPA composites membranes were made with the determination $\mathrm{Na}^{+}$and $\mathrm{K}^{+}$ions, independently. Toward this purpose, the membranes were then soaked for 24 $\mathrm{h}$ in a $1.00 \mathrm{M} \mathrm{NaCl}$ and $\mathrm{KCl}$ solution to ion exchange $\mathrm{H}^{+}$with $\mathrm{Na}^{+}$and $\mathrm{K}^{+}$. The concentration of the ions $\left(\mathrm{Na}^{+}\right.$or $\left.\mathrm{K}^{+}\right)$was determined by atomic emission spectroscopy and are presented in TABLE I. IEC is the ratio of concentration of ions (mequ./gram of composite). IEC was estimated as detailed in literature [15] and is also presented in the TABLE I. It can be seen from the TABLE I that the IEC of the composite membrane decreases when compared with the Nafion membrane. However, only IEC of 0.23 mequ./g $\left(\mathrm{Na}^{+}\right)$and 0.39 mequ./g $\left(\mathrm{K}^{+}\right)$was observed for Nafion/PDPA-CM1 (TABLE I). No definite trend is observed when the polymerization time increases (TABLE I). The reason for the observed lower IEC for the Nafion/PDPA-CM is as follows. Upon polymerization, more and more positively charged PDPA moieties were formed inside the membrane. The cationic PDPA act as counterions for the sulfonate groups of the Nafion membrane. Hence, this would decrease the IEC of the membrane.

\section{CONCLUSION}

Composite membranes of Nafion with poly(diphenylamine) were prepared and characterized for its morphology, structure, ion-exchange capacity, thermal properties in order to get better understandings of the Nafion microstructure after modification with PDPA. It can be seen that depending on the polymerization conditions, it is possible to prepare a NafionPDPA composite membrane with different amount of PDPA in the membrane. The presence of PDPA on the surface as well as inside the microstructure is evident from FESEM and AFM analysis. In all, this study gives an insight on how the presence of PDPA could affect the Nafion morphology and transport properties. It could contribute to the understanding of the factors involved in the ionic transport through Nafion membranes and in the development of cation exchange membranes for fuel cells.

\section{ACKNOWLEDGMENT}

This research was supported by Kyungpook National University Bokhyeon Research Fund, 2015

\section{REFERENCES}

[1] Z. Xia, A. Buechtemann, Z. An, J. Jiang, R. Danz and A. Wedel, "Influence of charging conditions on permeability for the membrane of porous polytetrafluoroethylene (PTFE) film electret," J. Electrostat, vol. 63, pp. 387-398, 2005.

[2] K. Sopian and W. R. W. Daud, "Challenges and future developments in proton exchange membrane fuel cells," Renewable energy, vol. 31, pp. 719-727, April 2006.

[3] M. Rikukawa and K. Sanui, "Proton-conducting polymer electrolyte membranes based on hydrocarbon polymers" Prog. Polym. Sci. vol. 25 , pp. 1463-1502, December 2000.

[4] J. Kerres, W. Cui and S. Reichle, "New sulfonated engineering polymers via the metalation route. I. Sulfonated poly(ethersulfone) PSU Udel ${ }^{\circledR}$ via metalation-sulfination-oxidation,” J. Polym. Sci. Part A: Polym. Chem. vol. 34, pp. 2421-2438, September 1996.

[5] M. Elomaa, S. Hietala, M. Paronen, N. Walsby, K. Jokela, R. Serimaa, M. Torkkeli, T.Lehtinen, G. Sundholm and F. Sundholm, "The state of water and the nature of ion clusters in crosslinked proton conducting membranes of styrene grafted and sulfonated poly(vinylidene fluoride)," J. Mater. Chem., vol. 10, pp. 2678-2684, October 2000.

[6] N. Myake, J.S. Wainright and R.F. Savinell, "Evaluation of a Sol-Gel Derived Nafion/Silica Hybrid Membrane for Polymer Electrolyte Membrane Fuel Cell Applications: II. Methanol Uptake and Methanol Permeability,” J. Electrochem. Soc. vol. 148, pp. A905-A909, July 2001.

[7] J.-C. Lin, M. Ouyang, J.M. Fenton, H.R. Kunz, J.T. Koberstein and M.B. Cutlip, "Study of blend membranes consisting of NafionR and vinylidene fluoride-hexafluoropropylene copolymer," J. Appl. Polym. Sci. vol. 70, pp. 121-127, October 1998.

[8] L.J. Hobson, Y. Nakano, H. Ozu and S. Hayase, "Targeting improved DMFC performance,” J. Power Sources. vol. 104, pp. 79-84, January 2002 . 
[9] L.J. Hobson, H. Ozu, M. Yamaguchi and S. Hayase, "Modified nafion 117 as an improved polymer electrolyte membrane for direct methanol fuel cells," J. Electrochem. Soc. 2001, vol. 148, pp.A1185-A1190, September 2001.

[10] J. Won, H.H. Park, Y.J. Kim, S.W. Choi, H.Y. Ha, I.-H. Oh, H.S. Kim, Y.S. Kang and K.J. Ihn, "Fixation of nanosized proton transport channels in membranes ," Macromolecules 2003, vol. 36, pp. 322832345, April 2003.

[11] F.N. Buchi, B. Gupta, O. Haas and G.G. Scherer, "Study of radiationgrafted FEP-G-polystyrene membranes as polymer electrolytes in fuel cells,"Electrochim. Acta vol. 40, pp. 345-353, February 1995.

[12] H.S. Lee and J. Hong, "Chemical synthesis and characterization of polypyrrole coated on porous membranes and its electrochemical stability," Synthetic Met. vol. 113, pp. 115-119, June 2000.

[13] S. Tan and D. Belanger, "Characterization and transport properties of nafion/polyaniline composite membranes,"J. Phys. Chem. B, vol. 109, pp. 23480-23490, November 2005.

[14] S. Moravcova , Z. C. Lova and K. Bouzk, "Preparation of a novel composite material based on a nafion ${ }^{\circledR}$ membrane and polypyrrole for potential application in a pem fuel cell,” J. Appl. Electrochem. Vol. 35, pp. 991-997, October 2005.

[15] Y. A. Elabd, E, Napadensky, C,W, Walker and K,I Winey, "Transport properties of sulfonated poly(styrene-b-isobutylene-b-styrene) triblock copolymers at high ion-exchange capacities," Macromolecules, , vol. 39, pp. 399-407 December 2005.

[16] I. Becerik and F. Kadirgan, "Electro-oxidation of formic acid on highly dispersed platinum and perchlorate doped polypyrrole electrodes," J. Electrochem. Soc. vol. 148, pp. D 49- D 54, May 2001. 